(Received July 7, 1980)

\title{
UNIAXIAL ELONGATIONAL VISCOSITY AT A CONSTANT STRAIN RATE OF POLYBUTENE-1 MELT
}

\author{
By Kiyohito Koyama and Osamu Ishizuka \\ (Faculty of Engineering, Yamagata University, \\ 4-3-16 Jyonan, Yonezawa, 992, Japan)
}

\begin{abstract}
The measurement of elongational viscosity of polybutene-1 melt has been carried out at a constant strain rate with an elongational rheometer which measures simultaneously the diameter of elongating samples. Non-linearity parameter of the viscosity was calculated from the total elongational viscosity values by dividing with the values of linear parts. The non-linearity parameters of the elongational viscosity were almost independent of strain rate and temperature. Four rheological constitutive models of integral type were chosen and applied for the elongational flow at a constant strain rate. The chosen models were the Lodge model, the Bogue and White model, the Bernstein, Kearsley and Zapas model, and the Wagner model. These models predicted the non-linearity of the elongational viscosity at high strain rate well. However, the non-linearity parameter predicted from these constitutive models showed strong dependences on both strain rate and temperature.
\end{abstract}

\section{INTRODUCTION}

In a preceding paper $^{1}$ ) the elongational viscosity of polypropylene was studied by a measurement at a constant strain rate. The elongational viscosity ( $\lambda$ )-time curves could be divided into two parts: linear part and non-linear part. The linear part, which appeared at a small strain, was shown as a common curve in the elongational viscosity for various strain rate. The data in the linear part $\left(\lambda_{l}\right)$ could be sufficiently explained by the Lodge model ${ }^{2,3)}$ and the Rouse model ${ }^{4}$; the curve gave values three times of the shear viscosity-time curve at a low strain rate. The non-linear part, which appeared at a large strain, was shown as the deviation from the linear curve to the larger values. The non-linearity parameter $\left(\lambda_{n}\right)$ in the elongational viscosity was defined by $\lambda_{n}=\lambda / \lambda_{l}$. Then the non-linearity parameters were almost independent of strain rate and temperature, and could be written as

$$
\lambda_{n}=\exp \left(\alpha r^{*}\right)
$$

where $\alpha$ is a constant which shows the intensity of the non-linearity and $\gamma^{*}$ is the effective strain and is given by:

$$
\begin{array}{ll}
r^{*}=r-r_{0}, & r>r_{c} \\
r^{*}=0 & , r \leq r_{c}
\end{array}
$$

In this study, the elongational viscosity of polybutene-1 melt was measured at various strain rates and temperatures. A method characterizing the non-linearity which was proposed for polypropylene $^{1)}$ was checked by the results on polybutene-1. The elongational viscosity was calculated from the rheological constitutive equations reported by many investigators. ${ }^{2,3,5-9 \text { ) }}$

\section{EXPERIMENTAL}

\subsection{Materials}

A sample of polybutene-1 was provided by the ADEKA ARGUS Chemical Company. This sample (WITRON 1600S), designed by the manufacture as a film grade, contains a few parcent of ethylene sequences. The sample was received in the form of pellets. It was molded into a rod of 2.5 to $5 \mathrm{~mm}$ diameter by a laboratory screw extruder fitted with a gear metering pump at $200^{\circ} \mathrm{C}$. Care was taken for the uniformity of the rod. The intrinsic viscosity was $2.1 \mathrm{dl} / \mathrm{g}$ determined in ethylcyclohexane at $70^{\circ} \mathrm{C}$, and the Melt Index was 1.0 . The melting point determined by a DSC was $109^{\circ} \mathrm{C}$.

\subsection{Apparatus}

The apparatus for the elongational measurements at a constant strain rate were previously described in some detail. ${ }^{1)}$ The sample rod floating on a silicon oil was melted at a constant 
temperature for $10 \mathrm{~min}$ and was elongated with a constant strain rate by a pair of rotating clamps, or by two pairs of rotating clamps. The results reported in this paper were obtained from the measurements in a strain rate range from 0.005 to $0.5 \mathrm{sec}^{-1}$ and a temperature range from 130 to $180^{\circ} \mathrm{C}$.

The force measurements were carried out by a leaf spring and a differential transducer. The rheological elongational force was calculated by the measured force and frictional drag force in the force balance equation. ${ }^{1)}$

During the elongation experiments, the sample rod was photographed through the microscope and its diameter was determined. A constant strain rate was checked by plotting the natural logarithm of diameter against time." When the inhomogeneity in the elongational deformation, or the break of sample occurred, the measurements were stopped.

\section{RESULTS}

\subsection{Elongational viscosity-time relation}

Figure 1 illustrates the dependence of the elongational viscosity on the strain rate at $180^{\circ} \mathrm{C}$ for polybutene-1 melt. The elongational viscosity for a strain rate of $0.005 \mathrm{sec}^{-1}$ increases smoothly with time, reaches a constant value at about 100 $\mathrm{sec}$, and then upswings. For a higher strain rate the time to upswing is short. In general terms these results are similar to those of polypropylene ${ }^{1)}$ and branched polyethylene. ${ }^{10-14)}$ The upswing time of polybutene- 1 is slightly smaller than that of polypropylene for each strain rate. Recent results on branched polyethylene show that the elongational viscosity at a high strain rate has a steady state of which value is much larger than three times of zero shear viscosity, ${ }^{12,13)}$ or has a maximum value ${ }^{14)}$ at a large strain. However, the present results on polybutene- 1 do not show such steady state or maximum; the same trends found for polypropylene. ${ }^{1)}$

Figure 2 shows the influence of temperature on the elongational viscosity of polybutene-1 melt. Both the linear parts and the non-linear parts behave similarly to those of polypropylene. ${ }^{1)}$ The time taken to reach the steady state in the linear part increases with decreasing temperature. The upswing time of each strain rate is independent of

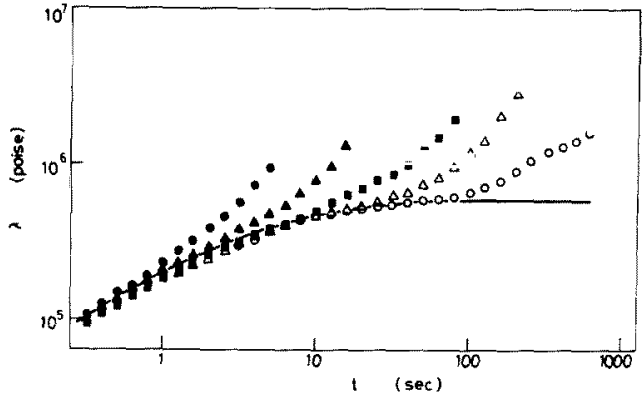

Fig. 1. Variation of the elongational viscosity with time at a constant strain rate at $180^{\circ} \mathrm{C}$ for polybutene-1. Strain rate $\left(\mathrm{sec}^{-1}\right):(0), 0.5$; (4), $0.2 ;(\mathbf{\Delta}), 0.05 ;(\Delta), 0.02 ;(0)$, 0.005 . Solid line is theoretical curve.

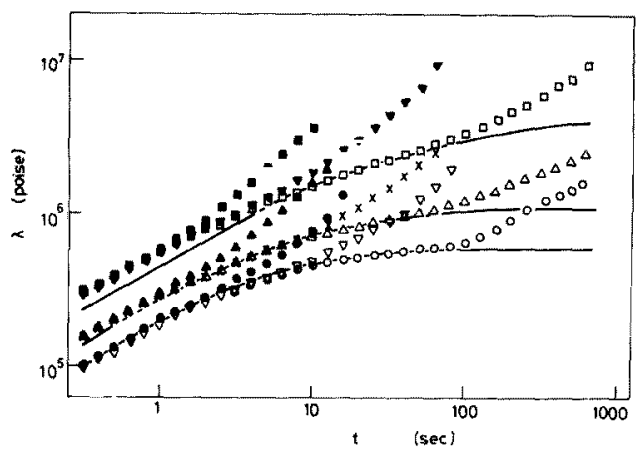

Fig. 2. Temperature dependence of the elongational viscosity-time curves at a constant strain rate for polybutene-1. Temperature $\left({ }^{\circ} \mathrm{C}\right)$, strain rate $\left(\mathrm{sec}^{-1}\right):(\mathbf{0}), 180,0.2$; $(\nabla), 180,0.05 ;(0), 180,0.005 ;$ ( $\wedge)$, $160,0.2 ;(x), 160,0.05 ;(\triangle), 160,0.005$; ( $\mathbf{\square}), 130,0.2 ;(\boldsymbol{\nabla}), 130,0.05 ;(\square), 130$, 0.005 . Solid lines are theoretical curves.

temperature. The relaxation modulus is calculated from the linear part and a master curve can be obtained from its temperature reduction. The activation energy estimated from the temperature dependence of the shift factor is $11 \mathrm{kcal} / \mathrm{mol}$. When the Rouse model ${ }^{4}$ ) is used to fit the master curve of the relaxation modulus, the maximum relaxation time results in $3 \mathrm{sec}$.

\subsection{Non-linearity in elongational viscosity}

The non-linearity parameter $\left(\lambda_{n}\right)$ is calculated as defined in the introduction. Typical plots of $\ln \lambda_{n}$ against strain are shown in Figure 3 and 4. For four strain rates and four temperatures, 


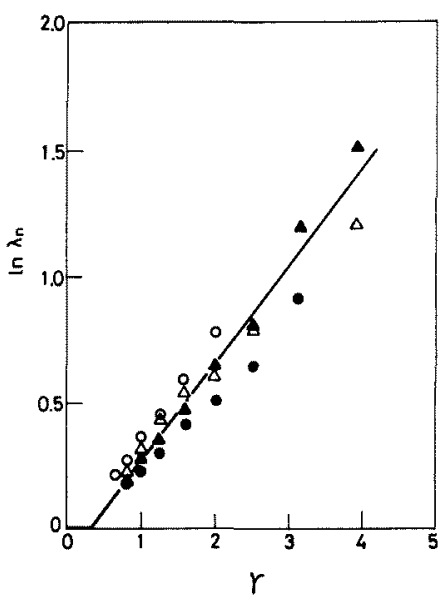

Fig. 3. Plots of the non-linearity parameter $\left(\lambda_{n}\right)$ versus elongational strain at $180^{\circ} \mathrm{C}$. Strain rate $\left(\sec ^{-1}\right):(0), 0.5 ;(0), 0.2 ;(\Delta)$, $0.05 ;$ ( $\Delta), 0.02$.

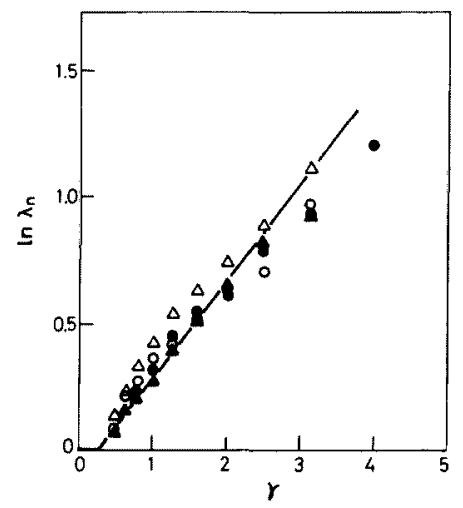

Fig. 4. Plots of the non-linearity parameter $\left(\lambda_{n}\right)$ versus elongational strain at a strain rate of $0.05 \mathrm{sec}^{-1}$. Temperature $\left({ }^{\circ} \mathrm{C}\right):(\odot), 180$;

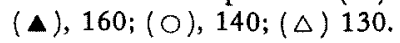

straight lines can be drawn through the data points. In the linear parts before the critical strain $\left(r_{c}\right)$ of 0.4 , the non-linearity parameter is unity, independent of strain rate. In the non-linear parts, $\ln \lambda_{n}$ is proportional to the strain. The slope of the straight line is found to be 0.41 . The critical strain and the slope of the straight line are almost independent of strain rate. Although the linear parts in the elongational viscosity change according to the variation of temperature, the non-linearity parameter does not depend on temperature. This behavior is the same as found for polypropylene except that the value of $r_{c}, 0.4$ is smaller than that for polypropylene (0.7).

\section{DISCUSSION}

For viscoelastic fluids, the stress may be expressed as a function of the deformation history. In recent years, many single-integral constitutive equations $^{2,3,5-8)}$ were reported, and applied to the non-linear response of polymer solutions and melts. Chen and Bogue ${ }^{6}$ had success with the Bernstein, Keasley and Zapas model, ${ }^{15,16)}$ the Bogue and White model, ${ }^{5,17)}$ and the Bird and Carreau model ${ }^{18)}$ in predicting transient shear stress overshoot behavior. Theoretical predictions for elongational viscosity-time curves have been carried out by Chang and Lodge, ${ }^{3)}$ and Wagner. ${ }^{19,20)}$ We select four models for the present study and discuss the non-linearity in the elongational viscosity.

Figure 5, 6 and 7 give the comparisons of the model predictions with the experimental data for polybutene- 1 melt. In these Figures, curve $\mathrm{L}$ follows the Lodge model, ${ }^{2,6)}$ which was motivated by the classical rubber elasticity theory. For the elongational viscosity-time relation upon imposition of a constant strain rate at time zero,

$$
\begin{aligned}
& \lambda(t)=\sum_{i=1}^{N} A_{i}\left(3+2 \tau_{i} v e^{u t}+\tau_{i} u e^{v t}\right) u^{-1} v^{-1} \\
& u=-\tau_{i}^{-1}+2 \dot{\gamma}, \quad v=-\tau_{i}^{-1}-\dot{\gamma}
\end{aligned}
$$

where $A_{i}$ and $\tau_{i}$ are adjustable parameters to fit the linear part in the elongational viscosity-time curve.

Curve BW is that of the Bogue and White model ${ }^{5,17)}$ wherein the non-linearities are introduced in the form of the average of the strain rate invariant. For the steady elongational flow, one can obtain the following equations;

$$
\begin{aligned}
\lambda(t)= & \sum_{i=1}^{N} \frac{G_{i}}{\dot{r}}\left\{\left(1+\frac{\varepsilon}{2}\right)\left(e^{u t}-e^{v t}\right)+\frac{\varepsilon}{2}\left(e^{p t}-e^{q t}\right)\right\} \\
& +\sum_{i=1}^{N} \frac{G_{i}}{\dot{\gamma} \tau_{i s}}\left\{\left(1+\frac{\varepsilon}{2}\right)\left(u^{-1} e^{u t}-v^{-1} e^{v t}\right)\right. \\
& +\frac{\varepsilon}{2}\left(p^{-1} e^{p t}-q^{-1} e^{q t}\right)-\left(1+\frac{\varepsilon}{2}\right)\left(u^{-1}-v^{-1}\right) \\
& \left.-\frac{\varepsilon}{2}\left(p^{-1}-q^{-1}\right)\right\} \\
u= & -\tau_{i \varepsilon}^{-1}+2 \dot{r}, \quad v=-\tau_{i \theta^{-1}}-\dot{r} \\
p= & -\tau_{i \varepsilon}^{-1}-2 \dot{r}, \quad q=-\tau_{i e}^{-1}+\dot{r}
\end{aligned}
$$




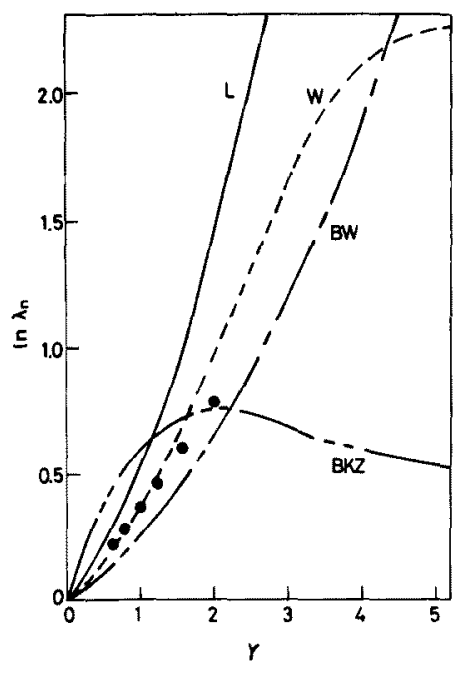

Fig. 5. Comparison of the model predictions with the experimental data for polybutene-1 at $\dot{r}=0.5 \mathrm{sec}^{-1}$ and at $180^{\circ} \mathrm{C}$.

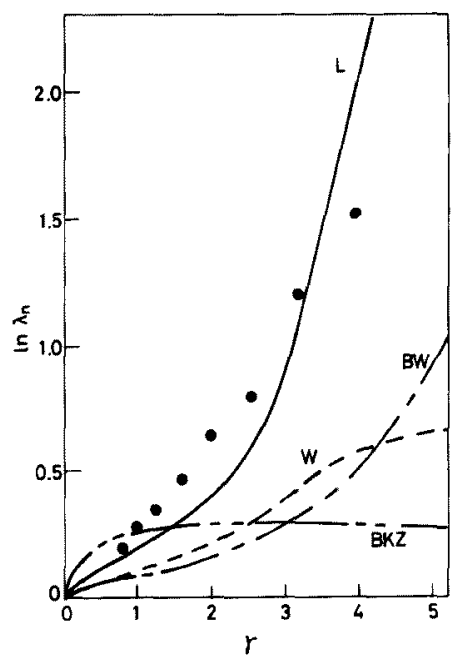

Fig. 6. Comparison of the model predictions with the experimental data for polybutene-1 at $\dot{r}=0.02 \sec ^{-1}$ and at $180^{\circ} \mathrm{C}$.

where $\tau_{i s}$ is called the effective time constants, which is given by

$$
\begin{aligned}
& \tau_{i \mathrm{~s}}=\frac{\tau_{i}}{1+a \tau_{i} \overline{\Pi_{\mathrm{d}}^{1 / 2}}} \\
& \overline{\Pi_{\mathrm{d}}^{1 / 2}}=\frac{1}{t-t^{\prime}} \int_{t^{\prime}}^{t} \Pi_{\mathrm{d}}^{1 / 2} d t^{\prime \prime}
\end{aligned}
$$

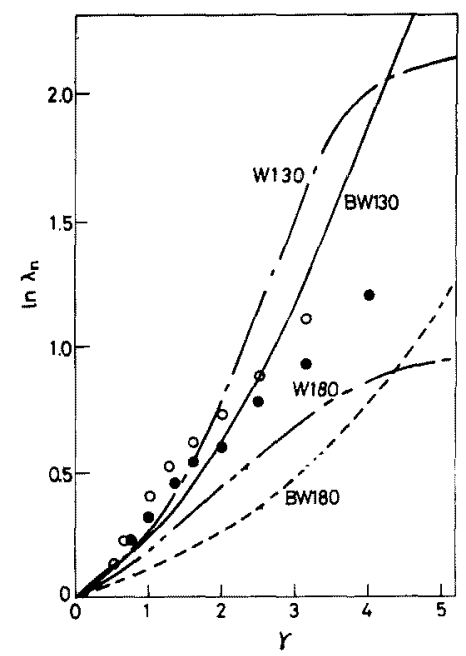

Fig. 7. Comparison of the model predictions with the experimental data for polybutene- 1 at $\dot{\gamma}=0.05 \mathrm{sec}^{-1}$ and at $130^{\circ} \mathrm{C}(O)$, and at $180^{\circ} \mathrm{C}(\mathrm{O})$.

in which $G_{i}$ and $\tau_{i}$ are adjustable parameters to fit the linear part and $a$ is the non-linear fitting parameter, and $\Pi_{d}$ is the second invariant of the rate of deformation tensor.

Curve $\mathrm{BKZ}$ is from the Bernstein, Kearsley and Zapas model ${ }^{15,16)}$ which was motivated from the strain energy consideration. For a step function type constant elongational strain rate experiments, this model results in

$$
\begin{aligned}
& \lambda(t)=\sum_{i=1}^{N} \frac{B_{i}}{\dot{\gamma}} e^{-t / \tau_{i}}\left\{l_{1}\left(e^{2 \dot{r} t}-e^{-\dot{r} t}\right)-l_{2}\left(e^{-2 \dot{r} t}-e^{\dot{\gamma} t}\right)\right\} \\
& +\sum_{i=1}^{N} \frac{B_{i}}{\dot{\gamma} \tau_{i}} \int_{0}^{t} e^{-\left(t-t^{\prime}\right) / \tau_{i}}\left\{k_{1}\left\{e^{2 \dot{\gamma}\left(t-t^{\prime}\right)}-e^{-\dot{\gamma}\left(t-t^{\prime}\right)}\right\}\right. \\
& \left.+k_{2}\left(e^{-2 \dot{r}\left(t-t^{\prime}\right)}-e^{\dot{r}\left(t-t^{\prime}\right)}\right\}\right) d t^{\prime} \\
& k_{1}\left(t-t^{\prime}\right)=-\frac{4.5}{\mathrm{I}\left(t-t^{\prime}\right)+\Pi\left(t-t^{\prime}\right)+3}-\frac{24}{\mathrm{I}\left(t-t^{\prime}\right)+15} \\
& k_{2}\left(t-t^{\prime}\right)=-\frac{4.5}{\mathrm{I}\left(t-t^{\prime}\right)+\mathrm{II}\left(t-t^{\prime}\right)+3}-\frac{24}{\mathrm{II}\left(t-t^{\prime}\right)+15} \\
& l_{1}(t)=k_{1}(t-0), \quad l_{2}(t)=k_{2}(t-0)
\end{aligned}
$$

where $B_{i}$ and $\tau_{i}$ are adjustable parameters to fit the linear part, and $I$ and II are, respectively, the first and second invariants of the Finger strain tensor.

Curve $W$ is from the Wagner model ${ }^{19,20)}$ which 
assumes that the non-linear memory function is expressible as a product of two functions; one is the rubber-liquid memory function, the other depends upon the relative strain and is called the damping function. In this case, the elongational viscosity is given by

$$
\begin{aligned}
\lambda(t) & =\sum_{i=1}^{N} \frac{h A_{i}}{\dot{\gamma} \dot{\tau}_{i}} e^{-t / \tau_{i}}\left(e^{2 i t}-e^{-\dot{r} t}\right) \\
& +\sum_{i=1}^{N} \frac{A_{i}}{\dot{\gamma}} \int_{0}^{t} h e^{-\left(t-t^{\prime}\right) / \tau_{i}}\left\{e^{2 \dot{r}\left(t-t^{\prime}\right)}-e^{-\dot{r}\left(t-t^{\prime}\right)}\right\} d t^{\prime} \\
h(r) & =\left\{e^{-6} e^{2 r}+\left(1-e^{-8}\right) e^{0.3 \gamma}\right\}^{-1}
\end{aligned}
$$

where $A_{i}$ and $\tau_{i}$ are the same constants as the Lodge model.

The adjustable parameters to fit the linear part are estimated for the data from 0.32 to $80 \mathrm{sec}$ in the experiment at $\dot{r}=0.005 \mathrm{sec}^{-1}$ and $180^{\circ} \mathrm{C}$. The results of the least squares data fitting are shown by the solid line in Figure 1. The values of estimated parameters are given in Table 1 for each model. The adjustable non-linear fitting parameter $a$ of the BW model is determined to be 0.3 and the value of $\varepsilon$ is 0 . The non-linearity of the elongational viscosity increased with decreasing the value of $a$, or with increasing the value of $\varepsilon$. It is seen in Figure 5 that the four rheological models predict the non-linearity of the elongational viscosity anyhow. However, in the case of low strain rate (Figure 6), although the experimental $\lambda_{n}-r$ relation is the same as that at high strain rate, some of the theoretical curves deviate conspicuously from the relation: the large discrepancies are seen between the data and the predictions of the $\mathrm{BW}$ model, the $\mathrm{W}$ model and the $\mathrm{BKZ}$ model. The $\mathrm{L}$ model is relatively good. The predictions from the $\mathrm{L}$ model and the $\mathrm{BW}$ model do not show any steady state or maximum value, but those from the $\mathrm{W}$ model and the BKZ model show a near steady state or a maximum value at relatively larger strain.

The effect of temperature on the elongational viscosity can be considered to be included in the parameters adjusted for the linear pari of the constitutive equations. In order to remain constant the relaxation strength, the time constant $\tau_{i}$ is replaced by $a_{\mathrm{T}} \tau_{i}^{\circ}$ in equations 4,5 , and 6 , and $\tau_{i}$ and $A_{i}$ are replaced, respectively, by $a_{\mathrm{T}} \tau_{i}^{\circ}$ and $A_{i} \% a_{\mathrm{T}}$ in equations 3 and 7 . Here, $a_{\mathrm{T}}$ is the shift factor, and $\tau_{i}^{\circ}$ and $A_{i}^{\circ}$ are the values at the reference temperature, which is $180^{\circ} \mathrm{C}$ in this study. The shift factors $a_{T}$ at $130^{\circ} \mathrm{C}$ and $160^{\circ} \mathrm{C}$ are chosen to fit the data of the linear part at longer times for $\dot{r}=0.005 \mathrm{sec}^{-1}$. The shift factor $a_{\mathrm{T}}$ is 5.5 at $130^{\circ} \mathrm{C}$ and 1.8 at $160^{\circ} \mathrm{C}$; from these values, an activation energy $\Delta H=12 \mathrm{kcal} / \mathrm{mol}$ is obtained.

The calculated values of the linear parts are also shown by the solid lines in Figure 2. This prediction gives a relatively good interpretation of the experimental data. The effects of temperature on the non-linearity are shown in Figure 7 . The theoretical values are shown for the BW model and the $W$ model. Other results from the $\mathrm{L}$ model and the BKZ model also have the similar dependence of temperature. It becomes evident from these results that the non-linearity parameters for the experimental data little change with the variation of temperature, but those predicted from constitutive equations have the strong dependence of temperature. That is, the non-linearities predicted from the constitutive equations are affected by the linear part in the elongational viscosity. On the contrary, although the linear parts of experimental data depend on temperature, the non-linearity parameters of experimental data are little affected by the linear part, i.e., by linear relaxation spectrum.

\section{CONCLUSION}

The method, which the present authors have proposed to characterize the non-linearity is successfully applied to the elongational viscosity of

Table 1. Model constants for the linear part of the elongational viscosity of polybutene-1 melt at $180^{\circ} \mathrm{C}$.

\begin{tabular}{cccccc}
\hline$\tau_{i}$ & 100 & 10 & 1 & 0.1 & 0.01 \\
$A_{i}$ & $1.38 \times 10^{0}$ & $9.46 \times 10^{2}$ & $7.43 \times 10^{4}$ & $1.16 \times 10^{6}$ & $2.08 \times 10^{7}$ \\
$G_{i}$ & $1.50 \times 10^{2}$ & $9.50 \times 10^{3}$ & $7.42 \times 10^{4}$ & $1.18 \times 10^{5}$ & $1.99 \times 10^{5}$ \\
$B_{i}$ & $1.16 \times 10^{2}$ & $9.36 \times 10^{3}$ & $7.47 \times 10^{4}$ & $1.13 \times 10^{5}$ & $2.31 \times 10^{5}$ \\
\hline
\end{tabular}


polybutene- 1 melt. The critical strain $\left(r_{0}\right)$ was 0.4 and the parameter $(\alpha)$ showing the intensity of the non-linearity is 0.41 . These non-linearity parameters are independent of strain rate and almost independent of temperature. These nonlinearity parameters can be estimated from the constitutive equations reported by some authors. The predicted results for the non-linearity qualitatively agree with the experimental results. However, the strain rate dependence and the temperature dependence of the calculated nonlinearity parameters fail to reproduce the experimental data.

\section{APPENDIX}

The general expression of the rheological equation of integral type has the form

$$
\sigma(t)=-P 1+\int_{-\infty}^{t}\left(m_{1} C^{-1}+m_{2} C\right) d t^{\prime}
$$

in which $\sigma$ is the total stress tensor, $P$ is pressure, 1 is the unit tensor, $C^{-1}$ is the Finger relative tensor, $C$ is the Cauchy relative tensor, $m_{1}$ and $m_{2}$ are the memory functions which express the dependence on strain history of the fluid.

For the case of stress growth upon imposition of a constant elongational strain rate $(\dot{r})$ at time zero, i.e.,

$$
\begin{aligned}
& C^{-1}=\left[\begin{array}{ccc}
e^{2 r} & 0 & 0 \\
0 & e^{-r} & 0 \\
0 & 0 & e^{-r}
\end{array}\right] \quad \boldsymbol{C}=\left[\begin{array}{ccc}
e^{-2 r} & 0 & 0 \\
0 & e^{\gamma} & 0 \\
0 & 0 & e^{r}
\end{array}\right] \\
& r=\dot{r}\left(t-t^{\prime}\right) \quad t^{\prime}>0 \\
& r=\dot{r} t \quad t^{\prime}<0
\end{aligned}
$$

The elongational viscosity is defined by

$$
\lambda=\frac{\sigma_{11}-\sigma_{22}}{\dot{r}}
$$

In the theory of Lodge, the memory function is

$$
\begin{aligned}
& m_{1}=\sum_{i=1}^{N} A_{i} e^{-\left(t-t^{\prime}\right) / t_{i}} \\
& m_{2}=0
\end{aligned}
$$

The memory functions of the Bogue and White model are expressed as

$$
\begin{aligned}
& m_{1}=\left(1+\frac{\varepsilon}{2}\right) \sum_{i=1}^{N} \frac{G_{i}}{\tau_{i \varepsilon}} e^{-\left(t-t^{\prime}\right) / \tau_{i e}} \\
& m_{2}=\frac{\varepsilon}{2+\varepsilon} m_{1}
\end{aligned}
$$

The BKZ model has the following form memory functions

$$
m_{1}=\frac{\partial U}{\partial I}, \quad m_{2}=\frac{\partial U}{\partial I}
$$

The functional form is

$$
U=-\frac{9}{2} \beta \log \frac{\mathrm{I}+\mathrm{II}+3}{9}-24 \beta \log \frac{\mathrm{I}+15}{\mathrm{I}+15}
$$

where

$$
\begin{aligned}
& \mathbf{I}=e^{2 \dot{r}\left(t-t^{\prime}\right)}+2 e^{-\dot{r}\left(t-t^{\prime}\right)} \\
& \text { II }=e^{-2 \dot{r}\left(t-t^{\prime}\right)}+2 e^{\dot{r}\left(t-t^{\prime}\right)}
\end{aligned}
$$

and the time-dependent term $\beta$ is given by

$$
\beta=-\sum_{i=1}^{N} \frac{B_{i}}{\tau_{i}} e^{-\left(t-t^{2}\right) / \tau_{i}}
$$

The memory functions of the Wagner model are

$$
\begin{aligned}
& m_{1}=\mu \cdot h, \quad m_{2}=0 \\
& \mu=\sum_{i=1}^{N} A_{i} e^{-(t-t) / \tau_{i}} \\
& h=\left\{e^{-6} e^{2 \tau}+\left(1-e^{-8}\right) e^{0.3 r}\right\}^{-1}
\end{aligned}
$$

Using these equations, one can calculate the elongational viscosity as the equations $3,4,5,6$ and 7 .

\section{ACKNOWLEDGEMENT}

The authors are indebted to Mr. T. Kawamura for his assistance in some of the experiments.

\section{REFERENCES}

1) O. Ishizuka and K. Koyama, Polymer, 21, $164(1980)$

2) A. S. Lodge, "Elastic Liquids" Academic Press, New York, 1964, Chap. 6

3) H. Chang and A. S. Lodge, Rheol. Acta, 11, 127 (1972)

4) P. E. Rouse, J. Chem. Phys., 21, 1292 (1953)

5) D. C. Bogue and J. L. White, Engineering Analysis of Non-Newtonian Fluids, Agardograph Series (1970)

6) I. J. Chen and D. C. Bogue, Trans. Soc. Rheol., 16, 59 (1972)

7) M. Yamamoto, "Buttai no Henkeigaku" Seibundo Shinkosha, Tokyo, 1972

8) M. Takahashi, T. Masuda and S. Onogi, Trans. Soc. Rheol., 21, 337 (1977)

9) H. C. Yen, L. V. McIntire, Trans. Soc. Rheol., 18, 495 (1974)

10) J. Meissner, Rheol. Acta, 8, 78 (1969)

11) J. Meissner, Rheol. Acta, 10, 230 (1971)

12) H. M. Laun and H. Muenstedt, Rheol. Acta, 15, 517 (1976)

13) H. M. Laun and H. Muenstedt, Rheol. Acta, 17, 415 (1978)

14) T. Raible, A. Demarmels and J. Meissner, Polymer Bulletin, 1, 397 (1979) 
15) B. Bernstein, E. A. Keasley and L. J. Zapas, Trans. Soc. Rheol., 7, 391 (1963)

16) L. J. Zapas, J. Res. Natl. Bur. Stds., 70A, 525 (1966)

17) D. C. Bogue, Ind. Eng. Chem. Fund, 5, 253 (1966)
18) R. B. Bird and P. J. Carreau, Chem. Eng. Sci., 23, 427 (1968)

19) M. H. Wagner, Rheol. Acta, 18, 33 (1979)

20) M. H. Wagner, J. Raible and J. Meissner, Rheol. Acta, 18, 427 (1979)

ポリブテンー1 溶融体の一定ひずみ速度下における一軸伸長粘度

山形大学工学部 小山清人, 石冢 修

伸長中での直佳および張力の同時測定が可能な装置を 使用して，ポリブテンー1溶融体の伸長粘度を睍定した。 伸長粘度の非線型パラメーターは線型領域の伸長粘度と 実測の全伸長粘度の比加計算した。得られた非線型性 のパラメーターはひずみ速度および温度にはほとんよ゙依 存しない。また，4つの積分型構成方程式を選び，一定 ひずみ速度下での伸長流動に応用した。それらのモデル
はロッジモデル，ボーグーホワイトモデル，バーンスタ イン・キースレイ・ザーパスモデルとワーグナーモデル である。これらのモデルは高ひずみ速度下での伸長粘度 の非線型性を良く説明できる。ところが，とれらのモデ ルから得られた非線型性のパラメーターはひずみ速度お よひ温度に強く依存した。 